\title{
Study on the Effect of Water Resource Constraint on the Economic Growth in Yangtze River Delta
}

\author{
Ze-yuan ZHU ${ }^{1,}$ a , Yu-xin XIA ${ }^{1, \text { b, * }}$ \\ ${ }^{1}$ School of Business Administration, HOHAl University, Changzhou Jiangsu, 213022, China \\ Aemail: 1549446976@qq.com, bemail: xiayuxin1998learn@163.com \\ ${ }^{*}$ Corresponding author: Yu-xin XIA
}

Keywords: Water resource constraint; Economic growth.

\begin{abstract}
Based on the improved cobb-douglas production function and Romer damping model, the paper analyzed the spatial differences of water resource growth damping in the Yangtze River delta region. The paper used the data of GDP, capital stock, number of employees and water resource input of provinces and cities from 2000 to 2017. The conclusions shows that from 2000 to 2017, the constraint effect of water resources in the Yangtze River delta region reduced the economic growth rate by $0.1135 \%$, and the damping coefficient and change trend of water resource growth in the Yangtze River delta region have obvious spatial differences.
\end{abstract}

\section{Introduction}

The Yangtze River delta region, including 26 prefecture-level cities in Shanghai, Jiangsu, Zhejiang, Anhui and three provinces, is the most urbanized region in China, with the urbanization rate of permanent residents reaching $66.66 \%^{[1-2]}$. In 2018, the senior triangle region generated 2.1 billion yuan of GDP, accounting for $23 \%$ of the national total, and is an important engine of China's economic growth. However, with the rapid development of economy, the constraint effect brought by the rapid consumption of various resources on regional economic growth has become increasingly prominent, becoming a "stumbling block" on the road of economic development ${ }^{[3]}$. Meanwhile, the optimal allocation of various resources among different industries also affects the coordinated development of regional economy to some extent. Resource constraints and social and economic development restrict and promote each other, so the realization of coordinated development of resources and economy is the key to promote sustainable development ${ }^{[4]}$. As a basic natural resource for human survival and a strategic resource for economic and social development, the consumption of water resources will profoundly affect the driving force of economic development ${ }^{[5]}$. It can be seen that sustainable economic and social development is closely related to water resources, and how to make scientific decisions to achieve coordinated development of water resources and economy is a common problem faced by urban agglomeration in the Yangtze River delta.

\section{Research methods}

New growth theory holds that the realization of the water resources constraint effect on economic growth path is because of natural water resources are insufficient or excessive use of water resources, and so on and so forth in utilization of water resources per capita is limited, so as to make the industry transformation and growth speed is lower than without water resource constraints, and its speed reduce degree to increase damping or tail $\mathrm{effect}^{[6]}$. This paper cites the economic growth model under environmental constraints proposed by Romer, an American economist, in 2001, and adds water resources to the cobb-douglas production function. When water resource constraints exist, $\mathrm{W}(\mathrm{t} 1)=\mathrm{nW}(\mathrm{t})$, that is, water resource increases year-on-year with the growth of labor force. In the above equation, $\mathrm{n}$ is the growth rate of labor force, and $\mathrm{W}(\mathrm{t})$ and $\mathrm{W}(\mathrm{t} 1)$ respectively refer to the amount of water resources input in year $t$ and year $t 1$. Based on the above assumptions, the damping model of water resources to economic growth is constructed by changing the long-term invariable situation of water resources in the original model: 


$$
\mathrm{Y}(\mathrm{t})=\mathrm{K}(\mathrm{t})^{\alpha} \mathrm{W}(\mathrm{t})^{\beta}[\mathrm{A}(\mathrm{t}) \mathrm{L}(\mathrm{t})]^{1-\alpha-\beta}
$$

In the above equation, $\mathrm{Y}(\mathrm{t})$ is the output in the TTH year; $\mathrm{K}(\mathrm{t}), \mathrm{W}(\mathrm{t}), \mathrm{A}(\mathrm{t})$ and $\mathrm{L}(\mathrm{t})$ are respectively capital input, water resource input, technological progress and labor input in the tyear. The product of $\mathrm{A}(\mathrm{t})$ and $\mathrm{L}(\mathrm{t})$ represents effective labor. The dynamics of capital, labor and labor effectiveness are consistent with the classical solow model. Alpha is capital output elasticity, beta is water resource output elasticity. By taking the logarithm of both sides of equation (1), equation (2) can be obtained:

$$
\operatorname{Ln} Y(t)=\alpha \operatorname{LnK}(t)+\beta \operatorname{Ln} W(t)+(1-\alpha-\beta)[\operatorname{Ln} A(t)+\operatorname{Ln} L(t)]
$$

Since the derivative of the logarithm of the variable with respect to time is the growth rate of this variable, and when the economic growth is on the equilibrium path, the output growth rate is considered to be equal to the capital growth rate, so the unit labor output growth rate when water resources are constrained can be calculated:

$$
g_{Y / L}^{b g p}(t)=\frac{\beta g_{\mathrm{W}}(t)+(1-\alpha-\beta) g_{A}(t)-\beta g_{\mathrm{L}}(t)}{1-\alpha}
$$

Growth rate of unit labor output under the condition that water resources are not constrained:

$$
\tilde{g}_{Y / L}^{b g p}(t)=\frac{\beta \widetilde{g}_{\mathrm{W}}(t)+(1-\alpha-\beta) g_{A}(t)-\beta g_{\mathrm{L}}(t)}{1-\alpha}
$$

Here, $g w(t), g A(t)$ and $g L(t)$ represent the growth rates of $\mathrm{W}, \mathrm{A}$ and $\mathrm{L}$ respectively. According to the definition of growth damping, the growth damping caused by water resource constraint is the difference between the growth rate of unit labor output under the condition that water resource is not constrained and under the condition of constraint, namely, the above formula (3) - formula (4). Under the path of balanced growth, let, and the formula for calculating the damping coefficient of water resource growth is:

$$
\mathrm{Z}=\frac{\beta(\mathrm{n}-\mathrm{w})}{1-\alpha}
$$

Here, $\mathrm{Z}$ is the growth damping generated by water resource constraint; alpha and beta are the output elasticity of capital and water resource respectively; $\mathrm{n}$ is the growth rate of labor force; $\mathrm{w}$ is the actual growth rate of water resource. According to the formula, the damping of water resource growth is positively correlated with capital output elasticity, water resource output elasticity and labor productivity, and negatively correlated with the actual growth rate of water resource.

\section{Empirical analysis}

\subsection{Ridge regression analysis}

In this paper, the ridge regression method is used to carry out regression processing on the inter-provincial panel data. The results show that the elasticity coefficient of capital output is 0.452 and that of water resource output is 0.102 , so the average damping coefficient of water resource growth in the Yangtze River delta region from 2000 to 2017 is about $0.113 \%$.

\subsection{Overall analysis}

The results show that the average damping coefficient of water resource growth in the Yangtze River delta region from 2000 to 2017 is about $0.113 \%$. The data shows that the economic growth rate of the Yangtze River delta region is $0.113 \%$ lower than that without water resources constraint due to the constraint of water resources.

\subsection{Analysis of spatial differences}

The results of damping coefficient of inter-provincial water resource growth and elastic coefficient of other factors in the older triangle region from 2000 to 2017 are shown in table 3. It is not difficult to find that three of the four provinces and cities in the Yangtze River delta region have obvious damping of water resource growth during the study period. The damping of water resources growth in anhui province was negative $(-0.361 \%)$, indicating that the economic growth of anhui province was not significantly constrained by water resources during the study period. 
Tab.1 The growth damping effect

\begin{tabular}{cccccccc}
\hline Province & $\mathbf{K}$ & $\mathbf{W}$ & $\mathbf{n}$ & $\mathbf{w}$ & $\boldsymbol{\beta}(\mathbf{n}-\mathbf{w})$ & $\mathbf{1 - \alpha}$ & Drag \\
\hline Shanghai & 0.524 & 0.042 & 0.043371026 & -0.00197392 & 0.001904488 & 0.476 & 0.004001025 \\
Jiangsu & 0.562 & -0.012 & 0.017132439 & 0.026780521 & 0.000115777 & 0.438 & 0.000264331 \\
Zhejiang & 0.575 & 0.103 & 0.019526053 & -0.006676185 & 0.00269883 & 0.425 & 0.006350189 \\
Anhui & 0.45 & 0.141 & 0.015547634 & 0.029637652 & -0.001986693 & 0.55 & -0.003612168 \\
\hline
\end{tabular}

\section{Conclusions and Suggestions}

\subsection{Research conclusions}

From 2000 to 2017, the constraint effect of water resources in the Yangtze River delta region reduced the economic growth rate by $0.1135 \%$ compared with that without water resources restrictions. Capital output elasticity and water resource output elasticity are both positive, and the former figure is relatively large, indicating that economic growth in the Yangtze River delta region is still constrained by capital and water resource, which is more dependent on capital and water.

From the differences of water resource growth damping between provinces and cities, the damping coefficient and change trend of water resource growth in the Yangtze River delta region have obvious spatial differences, among which the growth rate of labor force in zhejiang province, Shanghai province and jiangsu province is not in harmony with the growth rate of water resource, which makes the water resource constraint significant.

\subsection{Recommendations}

\subsubsection{Improve the utilization efficiency of water resources and reduce the output elasticity of water} resources.

First, develop new operating technologies and water-saving technologies to improve irrigation and drainage systems in various areas. Secondly, the current water shortage problem in China is composed of both water and water scarcity. While paying attention to restricting the amount of water resources, alleviating the water shortage problem will effectively reduce the existing contradiction between supply and demand of water resources.

\subsubsection{Optimize the labor force structure and improve the quality of employees}

First, increase the training and introduction of high-tech personnel and high-level innovative personnel, improve the employment policy and innovation incentive mechanism. Secondly, provinces and cities should make full use of innovative resources such as universities and scientific research institutes to promote the coordinated development of industry, education and research institutes, encourage high-quality employment personnel to transfer to the second and third industries.

\subsubsection{Increase capital input and strengthen technical support.}

We will make rational arrangements for capital input in light of the development of industries in various regions, and actively guide capital flows to the development of modern agriculture, new and high technologies, and provide ecological compensation to economically underdeveloped regions. Secondly, provinces and cities should attach great importance to the development of key and core technologies. Led and guided by science and technology departments, provinces and cities focuses on the research and development of advanced irrigation and dredging technologies, development technologies of available water resources, sewage and wastewater purification and treatment and other cutting-edge technologies. 


\section{References}

[1] Xu liting, yao shimou, Chen shuang, xu yu. Ecological city evaluation under high-quality development -- a case study of urban agglomeration in the Yangtze River delta [J/OL]. Geographical science :1-102019.08.004.

[2] Zhang xin-lin, qiu fangdao, wang changjian, wang pei-shun. Spatial spillover effect of industrial ecological efficiency in urban agglomeration of the Yangtze River delta and its influencing factors [J]. Resources and environment of the Yangtze River basin,2019,28(08):1791-1800.

[3] Zhao yali. Water resource constraints on urban construction land expansion in the Yangtze River delta region [J]. China population, resources and environment,2016,26(05):123-128.

[4] Lu xi, xu changxin. Dynamic efficiency and absolute beta convergence of water resources utilization in the Yangtze River economic belt -- based on three-stage dea-malmquist index method [J]. Resources and environment in the Yangtze River basin,2017,26(09):1351-1358.

[5] Liang hanwei, ni yueqi, dong liang, et al. Decoupling between economic growth and resource consumption -- a comparative study of China, Japan and the United States from an evolutionary perspective [J]. China population, resources and environment, 2008,28(05):8-16.

[6] Ma hailiang, xu jia, wang zhongyun. Research on water resources utilization in China's urbanization process [J]. Resources science,2014,36(02):334-341.

[7] Wan yongkun, dong suocheng, wang junni, et al. Study on the damping effect of water and soil resources on economic growth in Beijing [J]. Resources science,2012,34(03):475-480. 